\title{
Association of the genes for tumor necrosis factor- $\alpha$ and myelin basic protein with delayed encephalopathy after acute carbon monoxide poisoning
}

\author{
S.G. Li ${ }^{1 *}$, W.Q. Li ${ }^{2 *}$, J.K. Wang ${ }^{2}$, H.Y. Zhang ${ }^{2}$, W. Li ${ }^{2}$, P. Zhang', \\ X.H. Wang ${ }^{3}$, H.X. Zhang ${ }^{1}$, J.P. Gu ${ }^{1}$ and R.J. Gu ${ }^{1,2}$ \\ ${ }^{1}$ Department of Neurology, Second Affiliated Hospital, \\ Xinxiang Medical University, Xinxiang, China \\ ${ }^{2}$ Henan Key Lab of Biological Psychiatry, \\ Xinxiang Medical University, Xinxiang, China \\ ${ }^{3}$ Xinxiang Central Hospital, Xinxiang, China \\ *These authors contributed equally to this study. \\ Corresponding author: R.J. Gu \\ E-mail: gurenjun1961@yahoo.com.cn
}

Genet. Mol. Res. 11 (4): 4479-4486 (2012)

Received January 30, 2012

Accepted July 6, 2012

Published December 19, 2012

DOI http://dx.doi.org/10.4238/2012.December.19.1

\begin{abstract}
There is structural damage to myelin and secondary immune injury in the development of delayed encephalopathy after acute carbon monoxide (CO) poisoning (DEACMP). In order to assess the role of genetic factors in this mechanism, we studied the association between tumor necrosis factor- $\alpha 308$ (TNF- $\alpha 308$ ) and myelin basic protein (MBP) 5'-side tetranucleotide repetitive sequence (TGGA) $\mathrm{n}$ gene polymorphism and DEACMP. We selected 109 DEACMP patients from the Han population in the Northern Henan Province as the case group, and 115 patients without delayed encephalopathy (called the acute $\mathrm{CO}$ poisoning group or the control group). There were no significant differences in TNF- $\alpha 308$ and MBP 5'-side TGGA n genotype
\end{abstract}


distribution and allele frequency between the DEACMP group and the acute $\mathrm{CO}$ poisoning group (all $\mathrm{P}>0.05$ ). When the population was stratified by gender, only the MBP 5'-side TGGA $n$ allele frequency was significantly different, and the frequency of allele L in the DEACMP group was significantly higher than that of the acute $\mathrm{CO}$ poisoning group in males $\left(\chi^{2}=4.089, \mathrm{P}=0.043\right.$, odds ratio $=2.103,95 \%$ confidence interval $=1.014-4.363)$. The results showed that there was association between MBP 5'-side TGGA $n$ gene polymorphism and DEACMP, and that allele L could increase the risk of occurrence in male patients with DEACMP. DEACMP may be the result of interaction of environmental and genetic factors.

Key words: Carbon monoxide poisoning; Encephalopathy; Tumor necrosis factor- $\alpha$; Myelin basic protein; Gene polymorphism

\section{INTRODUCTION}

Acute carbon monoxide ( $\mathrm{CO}$ ) poisoning is a common occupational and living lifestyle poisoning that can damage body tissues and cells, mainly causing dysfunction of the central nervous system (CNS) and the cardiovascular system (Ye and Lu, 2004). Some patients with acute $\mathrm{CO}$ poisoning become conscious after treatment, reach a normal or near-normal latent phase after 3-60 days (mean 23.80 \pm 14.00 days), and then suffer delayed encephalopathy after acute CO poisoning (DEACMP). Patients with DEACMP experience neuropsychiatric symptoms such as dementia, mental disorders, and extrapyramidal symptoms.

To date, clinical studies on DEACMP remain at the cerebrospinal fluid and blood biochemical level (Gu et al., 2005; Zhang et al., 2007; Kamijo et al., 2007; Zhen et al., 2008). These clinical studies were easily affected by the physiological conditions of the body and were difficult to replicate because of the interference between indicators. DEACMP may be the outcome of acute $\mathrm{CO}$ poisoning-induced brain immune damage and apoptosis. However, the occurrence of DEACMP varies greatly even among patients of similar age, gender, and degree of intoxication, suggesting that individual circumstances and genetic factors play an important role in its manifestation.

The pathological changes caused by DEACMP are mainly symmetric malacia of the bilateral globus pallidus, extensive demyelination of brain white matter, and some irreversible damage to the hippocampus (Thom et al., 2004). Preliminary pathological changes caused by DEACMP, including a wide range of white matter demyelination and late pathological changes, i.e., brain atrophy, are similar to those caused by multiple sclerosis (MS). DEACMP and MS are both acquired demyelinating diseases of the CNS and have much in common with respect to pathological lesions of the brain.

Previous studies (Gu et al., 2001, 2002, 2005; Zhang et al., 2007; Zhen et al., 2008) have demonstrated significant differences of myelin basic protein (MBP), neuron-specific enolase, TNF, interleukin, and other immune cytokines in serum and cerebrospinal fluid in DEACMP development, suggesting the existence of MBP-mediated immune damage. This is similar to the pathogenesis of MS.

No research on the DEACMP gene has been reported yet. The research on the suscep- 
tibility gene polymorphism of MS is mainly focused on immunity-related genes and myelin structural genes. By retrieving and comparing genome-wide association research literature on MS (Pihlaja et al., 2003; Hafler et al., 2007; Sarial et al., 2008; Australia and New Zealand Multiple Sclerosis Genetics Consortium, 2009), and in the light of previous studies on a blood biochemical level, the MBP gene 5'-side TGGA n and TNF- $\alpha$ gene 308 site (TNF- $\alpha 308$ ) were selected to investigate the relationship between gene polymorphism and genetic susceptibility to DEACMP in the present study.

\section{MATERIAL AND METHODS}

\section{Subjects}

There were 109 patients in the DEACMP group ( 55 men, 54 women), ranging from 42 to 89 years (mean $59.68 \pm 9.72$ years). A total of 32 cases had no formal education, 41 had primary school education, and 36 had middle school education or higher. Coma happened after acute CO poisoning and lasted for $2-72 \mathrm{~h}$ (mean $16.09 \pm 15.13 \mathrm{~h}$ ), and the interval from consciousness after acute $\mathrm{CO}$ poisoning to occurrence of delayed encephalopathy was 7-45 days (mean $20.27 \pm 9.43$ days). There were also 115 patients without delayed encephalopathy called the acute $\mathrm{CO}$ poisoning group or the control group ( 50 men, 65 women), with ages ranging from 40 to 84 years (mean $56.12 \pm 7.38$ years). A total of 34 cases had no formal education, 39 had primary school education, and 42 had middle school education or higher. Coma happened after acute $\mathrm{CO}$ poisoning and lasted for $1-51 \mathrm{~h}$ (mean $6.78 \pm 7.49 \mathrm{~h}$ ). All patients in this group were monitored for over 90 days and no DEACMP was observed. Both groups of patients were from the Han population of the Northern Henan Province. The informed consent of all patients and their families were obtained. Age, gender, and educational level were all comparable between these two groups.

\section{Genotyping}

In the study, 5-mL samples of anticoagulant elbow vein blood were collected from each DEACMP patient after they had fasted from 6:00 to 8:00 am and from each acute CO poisoning patient within $2 \mathrm{~h}$ after they had recovered full consciousness. The blood samples were stored at $-70^{\circ} \mathrm{C}$. All DNA samples were extracted using a TIANGEN blood genome DNA extraction kit (China). TNF- $\alpha 308$ polymorphism analysis was conducted following the methods described by Tarkowski (2000) and Lu et al. (2008). TNF1 5'-AGGCAATAGGTTTTGAGGGCCATG-3' was designated as the upstream primer and TNF2 5'-ACACACAAGCATCAAGGATACC-3' as the downstream primer (synthesized by Takara Biotechnology Co., Ltd., Dalian, China) for the TNF- $\alpha 308$ promoter region. The amplified fragment measured $143 \mathrm{bp}$. The total volume of the PCR system was $25 \mu \mathrm{L}$, which was composed of $12.5 \mu \mathrm{L}$ EmeraldAmp $^{\mathrm{TM}}$ PCR Master Mix (twice concentrated premixed PCR kit with various enzymes, buffer, and dNTP mixture), $5 \mu \mathrm{L}$ DNA template, $1 \mu \mathrm{L} 10 \mu \mathrm{M}$ each of the upstream and downstream primer, and $5.5 \mu \mathrm{L}$ sterilized distilled water $\left(\mathrm{dH}_{2} \mathrm{O}\right)$. The amplification procedure was as follows: 1) pre-denaturation at $95^{\circ} \mathrm{C}$ for $5 \mathrm{~min}$; 2) 30 thermal cycles at $95^{\circ} \mathrm{C}$ for $30 \mathrm{~s}, 58.8^{\circ} \mathrm{C}$ for $50 \mathrm{~s}$, and $72^{\circ} \mathrm{C}$ for $90 \mathrm{~s} ; 3$ ) extension at $72^{\circ} \mathrm{C}$ for $5 \mathrm{~min}$. The total volume of the enzyme system was $10 \mu \mathrm{L}$, containing 3 $\mu \mathrm{L}$ PCR products, $0.5 \mu \mathrm{L} 10 \mu \mathrm{g} / \mu \mathrm{L}$ endonuclease StyI, $1 \mu \mathrm{L} 10 \mathrm{X}$ RE buffer, $0.1 \mu \mathrm{L} 10 \mu \mathrm{g} / \mu \mathrm{L}$

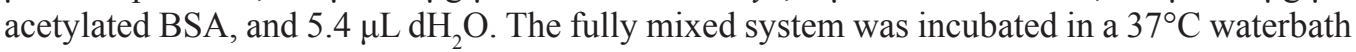


for $1.5 \mathrm{~h}$, and the digestion was terminated after incubation at $72^{\circ} \mathrm{C}$ for $10 \mathrm{~min}$. Separated by $2.0 \%$ agarose gel electrophoresis, the resulting images were screened and saved by a BTS20. M-type gel documentation system (USA).

MBP polymorphism analysis was conducted according to the methods of Guerini et al. (2003), with MBP1 5'-ATATGTGGATGGATGGATGACGAAT-3' designated as the upstream primer and MBP2 5'-CAGGATTCACTCACATATTCCTG-3' as the downstream primer (synthesized by TaKaRa Biotechnology Co., Ltd.) for 5'-side TGGA $n$ at the first exon region. The sizes of the amplified fragments were 420 and $380 \mathrm{bp}$, respectively. The total volume of the PCR system was 25 $\mu \mathrm{L}$, composed of $12.5 \mu \mathrm{L}$ EmeraldAmp ${ }^{\mathrm{TM}}$ PCR Master Mix, $5 \mu \mathrm{L}$ DNA template, $1 \mu \mathrm{L} 10 \mu \mathrm{M}$ each of the upstream and downstream primer, and $5.5 \mu \mathrm{L} \mathrm{dH_{2 }} \mathrm{O}$. The amplification procedures were as follows: 1) pre-denaturation at $95^{\circ} \mathrm{C}$ for $5 \mathrm{~min}$; 2) 30 thermal cycles at $94^{\circ} \mathrm{C}$ for $30 \mathrm{~s}, 61^{\circ} \mathrm{C}$ for $50 \mathrm{~s}$, and $72^{\circ} \mathrm{C}$ for $90 \mathrm{~s}$, and 3) extension at $72^{\circ} \mathrm{C}$ for $5 \mathrm{~min}$. Separated by $1.5 \%$ agarose gel electrophoresis, the resulting images were screened and saved by a BTS-20.M-type gel documentation system.

\section{Statistical analysis}

Analyses were conducted using SPSS13.0 for Windows (SPSS Inc., USA). The compatibility of the genotype distribution with the Hardy-Weinberg equilibrium was checked with the chi-square goodness-of-fit test. The direct counting method was used for the genotype and allele counts of TNF- $\alpha 308$ and MBP, as well as the calculation of genotype and allele frequencies. Comparison between the two groups was performed with the $\chi^{2}$ test. The odds ratio (OR) and a $95 \%$ confidence interval $(95 \% \mathrm{CI})$ were chosen to assess the risk of DEACMP.

\section{RESULTS}

As seen in Table 1, no significant differences were found in the Hardy-Weinberg equilibrium test between the two groups (all $\mathrm{P}>0.05$ ), which indicated that both groups were representative. Additionally, there were no significant differences in TNF- $\alpha 308$ and MBP 5 '-side TGGA $n$ genotype distribution and allele frequency between the two groups (all $\mathrm{P}>$ 0.05 , Table 2 ). When the population was stratified by gender, no significant differences in the TNF- $\alpha 308$ genotype distribution and allele frequency between the two groups were observed (all P > 0.05, Table 3). MBP genotype distribution of LL, LS, and SS revealed insignificant differences between female patients of the two groups; however, the allele L frequency (0.873) in the male DEACMP group was significantly higher than the allele L frequency $(0.765)$ in the male acute $\mathrm{CO}$ poisoning group $\left(\chi^{2}=4.089, \mathrm{OR}=2.103, \mathrm{P}=0.043\right)$ (Table 4). However, the significance was lost after Bonferroni's multiple comparisons. There was only a nominal association between DEACMP and MBP gene polymorphism.

The interaction between TNF- $\alpha$ and MBP genotypes and the correlation with DEACMP were not significantly different (all $\mathrm{P}>0.05$, Table 5 ), suggesting that the interaction among different genotypes had no impact on the genetic susceptibility to DEACMP.

The highly conserved MBP gene spans 32-34 kb on chromosome 18q22-23. It has seven exons, and TGGA $\mathrm{n}$ is located at the $1.0-\mathrm{kb}$ region of the 5 '-end of the first exon and others. The copy number manifested polymorphism, on which the study on demyelinationassociated genetic diseases has emphasized (Guerini, et al. 2003).

The distribution of the MBP 5'-side TGGA $n$ genotype and allele frequencies in both 
groups were compared and showed no significant differences.

Table 1. Genotype and allele frequencies of the gene polymorphism locus in delayed encephalopathy after acute carbon monoxide poisoning (DEACMP) group and acute carbon monoxide (CO) poisoning group.

\begin{tabular}{|c|c|c|c|c|c|c|c|c|c|c|c|c|c|c|c|c|}
\hline \multirow[t]{3}{*}{ SNP } & \multirow[t]{3}{*}{ dbSNP ID } & \multirow[t]{3}{*}{ Allele $(\mathrm{D} / \mathrm{d})^{\mathrm{a}}$} & \multicolumn{6}{|c|}{ DEACMP } & \multicolumn{6}{|c|}{ Acute $\mathrm{CO}$ poisoning } & \multicolumn{2}{|l|}{$\mathrm{P}^{\mathrm{c}}$} \\
\hline & & & \multirow[t]{2}{*}{$\mathrm{N}^{\mathrm{b}}$} & \multirow[t]{2}{*}{ HWE (P) } & \multicolumn{3}{|c|}{ Genotype } & \multirow[t]{2}{*}{ MAF } & \multirow[t]{2}{*}{$\mathrm{N}^{\mathrm{b}}$} & \multirow[t]{2}{*}{ HWE (P) } & \multicolumn{3}{|c|}{ Genotype } & \multirow[t]{2}{*}{ MAF } & \multirow[t]{2}{*}{ Genotype } & \multirow[t]{2}{*}{ Allel } \\
\hline & & & & & DD & $\mathrm{Dd}$ & dd & & & & DD & Dd & dd & & & \\
\hline 1 & TNF- $\alpha 308$ & $\mathrm{G} / \mathrm{A}$ & 109 & 0.380 & 96 & 12 & 1 & 0.064 & 115 & 0.392 & 98 & 17 & 0 & 0.074 & 0.530 & 0.686 \\
\hline 2 & MBP (TGGA) & 1) $\quad L / S$ & 109 & 0.565 & 76 & 31 & 2 & 0.161 & 114 & 0.883 & 70 & 39 & 5 & 0.215 & 0.191 & 0.142 \\
\hline
\end{tabular}

${ }^{a}$ Major/minor allele, minor and major alleles are denoted by D and d, respectively. ${ }^{b}$ Number of samples which are well genotyped. ${ }^{\mathrm{C}} \mathrm{P}$ value evaluated by the $\chi^{2}$ test. $\mathrm{MBP}=$ myelin basic protein; HWE $=$ Hardy-Weinberg equilibrium; $\mathrm{MAF}=$ minor allele frequency.

Table 2. Genotype and allele frequencies of the association polymorphism locus from the chi-square test in female and male samples.

\begin{tabular}{|c|c|c|c|c|c|c|c|c|}
\hline Gender & dbSNP ID & Genotype & & & $P$ & Allele & & $\mathrm{P}$ \\
\hline \multirow[t]{6}{*}{ Female } & TNF- $\alpha 308$ & GG & GA & $\mathrm{AA}$ & 0.747 & $\mathrm{G}$ & $\mathrm{A}$ & 0.753 \\
\hline & DEACMP & 48 & 6 & 0 & & 102 & 6 & \\
\hline & Acute $\mathrm{CO}$ poisoning & 60 & 5 & 0 & & 125 & 5 & \\
\hline & MBP (TGGA) n & $\mathrm{L} / \mathrm{L}$ & $\mathrm{L} / \mathrm{S}$ & $\mathrm{S} / \mathrm{S}$ & 0.844 & $\mathrm{G}$ & A & 0.915 \\
\hline & DEACMP & 35 & 17 & 2 & & 87 & 21 & \\
\hline & Acute $\mathrm{CO}$ poisoning & 41 & 22 & 2 & & 104 & 26 & \\
\hline \multirow[t]{6}{*}{ Male } & TNF- $\alpha 308$ & GG & GA & $\mathrm{AA}$ & 0.134 & G & A & 0.244 \\
\hline & DEACMP & 48 & 6 & 1 & & 102 & 8 & \\
\hline & Acute $\mathrm{CO}$ poisoning & 38 & 12 & 0 & & 88 & 12 & \\
\hline & $\operatorname{MBP}(T G G A) n$ & $\mathrm{~L} / \mathrm{L}$ & $\mathrm{L} / \mathrm{S}$ & $\mathrm{S} / \mathrm{S}$ & 0.096 & G & A & 0.043 \\
\hline & DEACMP & 41 & 14 & 0 & & 96 & 14 & \\
\hline & Acute CO poisoning & 29 & 17 & 3 & & 75 & 23 & \\
\hline
\end{tabular}

$\mathrm{DEACMP}=$ delayed encephalopathy after acute carbon monoxide poisoning; $\mathrm{MBP}=$ myelin basic protein .

Table 3. Interaction of different genotypes between the delayed encephalopathy after acute carbon monoxide poisoning (DEACMP) group and the acute carbon monoxide $(\mathrm{CO})$ poisoning group.

\begin{tabular}{lllccc}
\hline & & \multicolumn{3}{c}{ TNF- $\alpha$} & \\
\cline { 3 - 4 } & & & $\mathrm{G} / \mathrm{G}$ & $\mathrm{G} / \mathrm{A}+\mathrm{A} / \mathrm{A}$ & \\
\hline MBP & $\mathrm{L} / \mathrm{L}$ & DEACMP (76) & 66 & 10 & $\chi^{2}=0.039 \mathrm{P}=0.843$ \\
& $\mathrm{~L} / \mathrm{S}+\mathrm{S} / \mathrm{S}$ & Acute CO poisoning (70) & 60 & 10 & \\
& DEACMP (33) & 30 & 3 & $\chi^{2}=0.066 \mathrm{P}=0.798$ \\
& Acute CO poisoning (44) & 38 & 6 & \\
\hline
\end{tabular}

$\overline{\mathrm{MBP}}=$ myelin basic protein.

Table 4. Comparison of genotype distribution and allele frequency between males in the two groups.

\begin{tabular}{lccccc}
\hline Groups & \multicolumn{3}{c}{ TNF- $\alpha 308$ genotype $(\mathrm{N}, \%)$} & \multicolumn{2}{c}{ TNF- $\alpha 308$ allele $(\mathrm{N}, \%)$} \\
\hline TNF- $\alpha 308$ & $\mathrm{G} / \mathrm{G}$ & $\mathrm{G} / \mathrm{A}$ & $\mathrm{A} / \mathrm{A}$ & $\mathrm{G}$ & $\mathrm{A}$ \\
DEACMP & $48(87.3)$ & $6(10.9)$ & $1(1.8)$ & $102(92.7)$ & $8(7.3)$ \\
Acute CO poisoning & $38(76.0)$ & $12(24.0)$ & $0(0.0)$ & $88(88.0)$ & $12(12.0)$ \\
Test value & $\chi^{2}=2.246, \mathrm{P}=0.134^{*}$ & $\chi^{2}=1.358, \mathrm{P}=0.244$ & $\mathrm{~L}$ & & $\mathrm{~S}$ \\
MBP & $\mathrm{L} / \mathrm{L}$ & $\mathrm{L} / \mathrm{S}$ & $\mathrm{S} / \mathrm{S}$ & $\mathrm{L}$ & $14(12.7)$ \\
DEACMP & $41(74.5)$ & $14(25.5)$ & $0(0.0)$ & $96(87.3)$ & $23(23.5)$ \\
Acute CO poisoning & $29(59.2)$ & $17(34.7)$ & $3(6.1)$ & $75(76.5)$ & \\
Test value & $\chi^{2}=2.779, \mathrm{P}=0.096^{* *}$ & $\chi^{2}=4.089, \mathrm{P}=0.043$ & & \\
\hline
\end{tabular}

*Statistical results for $\mathrm{G} / \mathrm{G}$ and $\mathrm{G} / \mathrm{A}+\mathrm{A} / \mathrm{A}$. **Statistical results for $\mathrm{L} / \mathrm{L}$ and $\mathrm{L} / \mathrm{S}+\mathrm{S} / \mathrm{S}$. DEACMP $=$ delayed encephalopathy after acute carbon monoxide $(\mathrm{CO})$ poisoning; $\mathrm{MBP}=$ myelin basic protein. 
Table 5. Interaction of different genotypes between the DEACMP group and the acute CO poisoning group.

\begin{tabular}{llcccc}
\hline & TNF- $\alpha$ & \multicolumn{3}{c}{ TNF- $\alpha$} & $\chi^{2}$ \\
\cline { 3 - 4 } & & G/G genotype & G/A+A/A genotype & & \\
\hline MBP & DEACMP (76) & 66 & 10 & 0.039 & 0.843 \\
L/L genotype & Acute CO poisoning (70) & 60 & 10 & & \\
MBP & DEACMP (33) & 30 & 3 & 0.066 & 0.798 \\
L/S + S/S genotype & Acute CO poisoning (44) & 38 & 6 & & \\
\hline
\end{tabular}

$\mathrm{MBP}=$ myelin basic protein.

\section{DISCUSSION}

The human TNF gene is located in the 7-kb region of the major histocompatibility complex of chromosome 6 . The products it encodes are TNF- $\alpha$ and TNF- $\beta$, and it exhibits a wide range of biological activities. The TNF gene polymorphism is featured as base pair transversion, and the TNF- $\alpha$ gene polymorphism locus is concentrated at its promoter region. Multiple sites in this region are polymorphic. The distributions of TNF- $\alpha 308$ genotype and allele frequencies at the promoter region between the two groups were not significantly different. They were also not statistically different when stratified by gender. There was no relationship between TNF- $\alpha 308$ gene polymorphism and DEACMP susceptibility.

The genotype and allele frequency in the acute $\mathrm{CO}$ poisoning control group were significantly different from the Italian population $(0.364,0.461,0.175 ; 0.594,0.406$, respectively) and the Russian population $(0.405,0.421,0.174 ; 0.615,0.385$, respectively) (Guerini et al., 2003). This indicated that the distribution of MBP gene polymorphisms was population-specific. TNF- $\alpha 308$ genotype (GG, GA, AA) frequency $(0.852,0.148,0$, respectively) and allele (G, A) frequency $(0.926,0.074$, respectively) in the acute $\mathrm{CO}$ poisoning control group were similar to those of the Han population $(0.888,0.105,0.007 ; 0.9021,0.0979$ and $0.843,0.129,0.028 ; 0.856$, 0.144 , respectively) in other studies (Jia et al., 2009), and significantly different from those of the Scandinavian population $(0.649,0.322,0.029 ; 0.810,0.190$, respectively) (Lindholm et al., 2008). This finding suggests that the distribution of the TNF- $\alpha 308$ gene is population-specific, and that GA and AA genotypes and allele frequency were different in the Han population.

Kroeger et al. (2000) and González et al. (2003) studied the impact of TNF- $\alpha 308$ GA polymorphism on TNF- $\alpha$ transcription and found that the TNF- $\alpha$ gene transcription efficiency significantly increased once $\mathrm{G} \rightarrow$ A mutation was observed. They concluded that the TNF- $\alpha 308$ A allele might be able to increase the TNF- $\alpha$ level in the blood through the promotion of TNF- $\alpha$ gene transcription, thus affecting susceptibility to the disease. Pu and Zeng (2009) and Lu et al. (2008) found that the TNF- $\alpha 308$ genotype (including GA and AA) could increase TNF- $\alpha$ transcription by increasing the transcriptional activity of the TNF- $\alpha$ promoter, thus promoting an inflammatory response. Although there was an abnormal expression of TNF- $\alpha$ in the pathogenesis of DEACMP, the current study did not find an association between TNF- $\alpha 308$ gene polymorphism and DEACMP. The reasons might be as follows: 1) sample size and racial differences: the TNF- $\alpha 308$ A allele distribution in the Han population was rather rare, and the insufficient sample size would cause significantly decreased frequencies of the GA and AA genotypes, thus resulting in insignificant differences; 2) the TNF gene locates in HLA-III genes and has a chain imbalance with some HLA haplotypes. These haplotypes may be related to TNF gene transcription and could play a predominant role, while the TNF gene may only play a supporting or synergistic role. 
Autoimmune diseases usually have a complex genetic model, and interactions between susceptibility genes have occurred (Bai et al., 2004). The relationship between different TNF- $\alpha$ and MBP genotypes with susceptibility to DEACMP was investigated in the present paper, but no such relationship was found. Different genotypes of TNF- $\alpha$ and MBP had no joint effect on genetic susceptibility to DEACMP.

In conclusion, the current research has shown that there is genetic susceptibility to DEACMP, and DEACMP is a kind of disease that results from the interaction between environmental factors and genetic background. More valuable discoveries can be expected through expanded sample size and further study.

\section{ACKNOWLEDGMENTS}

We sincerely thank the subjects for their participation in this study and the staff from Henan Key Laboratory of Bio-Psychiatry for their technical support. Research supported by the National Natural Science Foundation of China (\#81141071), the Key Technologies R\&D Program of Henan Department of Science and Technology (\#102102310152).

\section{REFERENCES}

Australia and New Zealand Multiple Sclerosis Genetics Consortium (2009). Genome-wide association study identifies new multiple sclerosis susceptibility loci on chromosomes 12 and 20. Nat. Genet. 41: 824-828.

Bai XF, Li O, Zhou Q, Zhang H, et al. (2004). CD24 controls expansion and persistence of autoreactive T cells in the central nervous system during experimental autoimmune encephalomyelitis. J. Exp. Med. 200: 447-458.

González S, Rodrigo L, Martinez-Borra J, Lopez-Vazquez A, et al. (2003). TNF- $\alpha$-308A promoter polymorphism is associated with enhanced TNF- $\alpha$ production and inflammatory activity in Crohn's patients with fistulizing disease. Am. J. Gastroenterol. 98: 1101-1106.

Gu RJ, Lu H, Hu SJ and Zhang XM (2001). The change of the CSF Ig and TNF- $\alpha$ in patients with delayed encephalopathy after acute carbon monoxide poisoning. J. Apoplexy Nervdus Dis. 18: 173-174.

Gu RJ, Chen Z, Zhang XM, Song JG, et al. (2002). The determination of neuron specific enolase and myelin basic protein in Geriatric patients with delayed encephalopathy after acute carbon monoxide poisoning. Chin. J. Geriatr. 21: 60-61.

Gu RJ, Wang XH, Zhang P, Lu H, et al. (2005). Change of the serum interleukin 6 in patients with delayed encephalopathy after acute carbon monoxide poisoning. Zhonghua Lao Dong Wei Sheng Zhi Ye Bing Za Zhi 23: 461-462.

Guerini FR, Ferrante P, Losciale L, Caputo D, et al. (2003). Myelin basic protein gene is associated with MS in DR4- and DR5-positive Italians and Russians. Neurology 61: 520-526.

Hafler DA, Compston A, Sawcer S, Lander ES, et al. (2007). Risk alleles for multiple sclerosis identified by a genomewide study. N. Engl. J. Med. 357: 851-862.

Jia A, Gong J, Li YC, Zuo XM, et al. (2009). Correlation of polymorphisms of the IL-1 promoter region and tumor necrosis factor- $\alpha$ gene with susceptibility of non-cardiac gastric cancer in a Han nationality of Shaanxi Chinese population. J. Xi an Jiaotong Univ. 1: 70-73.

Kamijo Y, Soma K and Ide T (2007). Recurrent myelin basic protein elevation in cerebrospinal fluid as a predictive marker of delayed encephalopathy after carbon monoxide poisoning. Am. J. Emerg. Med. 25: 483-485.

Kroeger KM, Steer JH, Joyce DA and Abraham LJ (2000). Effects of stimulus and cell type on the expression of the -308 tumour necrosis factor promoter polymorphism. Cytokine 12: 110-119.

Lindholm E, Bakhtadze E, Cilio C, Agardh E, et al. (2008). Association between LTA, TNF and AGER polymorphisms and late diabetic complications. PLoS One 3: e2546.

Lu MC, Yang KL, Tung CH, Huang KY, et al. (2008). Higher LPS-stimulated TNF- $\alpha$ mRNA levels in peripheral blood mononuclear cells from Chinese ankylosing spondylitis patients with -308G/A polymorphism in promoter region of tumor necrosis factor: association with distinct A33/B58/Cw10 haplotypes. Rheumatol. Int. 29: 189-195.

Lv ZQ and Sun B (2008). Association of TNF- $\alpha$ gene polymorphism with Graves ophthalmopathy. J. Shanxi Med. Univ. 39: 633-636.

Pihlaja H, Rantamaki T, Wikstrom J, Sumelahti ML, et al. (2003). Linkage disequilibrium between the MBP tetranucleotide 
repeat and multiple sclerosis is restricted to a geographically defined subpopulation in Finland. Genes Immun. 4: 138-146. $\mathrm{Pu}$ J and Zeng WY (2009). Relationship among TNF- $\alpha$ gene promoter -308 site polymorphism, the levels of maternal serum TNF- $\alpha$, and the mRNA expression placental TNF- $\alpha$ in preterm labor. Sichuan Da Xие Xие Baо Yi Xие Ban 40: 77-80.

Sarial S, Shokrgozar MA, Amirzargar A, Shokri F, et al. (2008). IL-1, IL-1R and TNF- $\alpha$ gene polymorphisms in Iranian patients with multiple sclerosis. Iran J. Allergy Asthma Immunol. 7: 37-40.

Tarkowski E, Liljeroth AM, Nilsson A, Ricksten A, et al. (2000). TNF gene polymorphism and its relation to intracerebral production of TNF- $\alpha$ and TNF- $\beta$ in AD. Neurology 54: 2077-2081.

Thom SR, Bhopale VM, Fisher D, Zhang J, et al. (2004). Delayed neuropathology after carbon monoxide poisoning is immune-mediated. Proc. Natl. Acad. Sci. U. S. A. 101: 13660-13665.

Ye RG and Lu ZY (2004). The Internal Medicine. 6th edn. People's Medical Publishing House, Beijing.

Zhang P, Gu RJ and Zhang F (2007). Changes of serum interleukin levels and its clinic significance in patients with delayed encephalopathy after acute carbon monoxide poisoning. J. Clin. Neurol. 20: 220-221.

Zhen L, Gu RJ and Zhang P (2008). Serum levels and clinical significance of IL in patients with delayed encephalopathy after acute carbon monoxide poisoning. Zhonghua Lao Dong Wei Sheng Zhi Ye Bing Za Zhi 26: 561-562. 